upon any feature to which he wishes to direct attention.

The arrangement of the device is shown in the subjoined figure:-

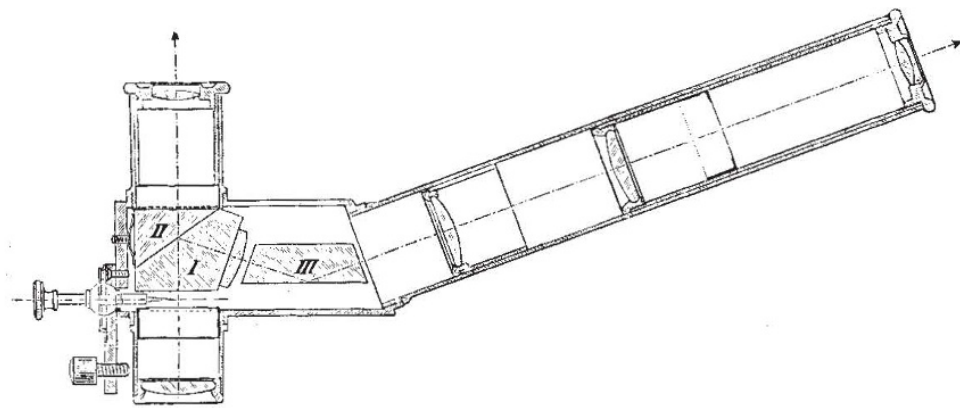

FIG. 2.-Demonstrating eyepiece. other moving organisms illuminated by means of a dark-ground condenser; it enables one to observe the object through the side eyepiece and to defer the exposure until a favourable moment presents itself.

This eyepiece makes the instrument to which it is attached into a binocular microscope in a new sense. Its use will certainly not be confined to laboratories; it will equally be a delightful acquisition to tyros discussing pondlife or other subjects in which amateurs take an interest. The 6-diameter power is to be preferred, and as the branch tube is not counterpoised, if the evepiece tubes do not fit tight it is better to use the microscope in a vertical position.
$I$ and $I I$ are two prisms in contact and mounted above the diaphragm between the field-lens and the eye-lens of the eyepiece. The prism $I$ has an isosceles cross-section, and its angles are $35^{\circ}, 35^{\circ}$, and $I I O^{\circ}$ respectively. The prism $I I$ is rectangular, and its angles are $35^{\circ}, 55^{\circ}$, and $90^{\circ}$. The prisms are placed with those faces in contact which subtend the angles of $90^{\circ}$ and $110^{\circ}$ in such a manner as to leave between them a very thin film of air. This film is inclined at an angle of $30^{\circ}$ to the axis of the eyepiece and partially reflects the emerging pencil of rays; about twothirds of the rays pass through the prisms, and one-third is reflected.

The image formed along the axis of the microscope is accordingly brighter than that produced by partial reflection. The centre line of the reflected pencil is inclined at an angle of $70^{\circ}$ to the axis of the microscope. $I I I$ is a prism the lower surface of which reflects the pencil upwards at a convenient angle for observation. In order that the two observers may not be in each other's way, the branch tube is fitted with a system of lenses which resembles a terrestrial eyepiece. The image as seen in the side tube is reversed with respect to that which appears in the axial eyepiece; but this scarcely affects the observer, since the oblique attachment of the side eyepiece changes the orientation of the field which is focussed through the principal eyepiece, as the image seen through it is brighter. The adjustment for one eyepiece furnishes a clearly defined image in the subsidiary eyepiece, provided the eyes of both observers can accommodate in a similar manner. The objective in conjunction with the field-lens below the double prism of the two eyepieces forms an image in the plane of the diaphragm below the double prism. This image and the pointer, being both in the plane of the diaphragm, are seen simultaneously in both eyepieces. The pointer can be moved backwards and forwards and turns on a pivot so that its extreme end can be set to any point in the field.

The new eyepiece is well adapted for the instantaneous photography of living bacteria and NO. 2264, VOL. 9I]

\section{STANDARDS AND TESTS FOR SEWAGE} AND SEWAGE EFFLUENTS.

THE eighth report of the Royal Commission on Sewage Disposal deals with the important question of standards and tests for sewage and sewage effluents discharging into rivers and streams. In their fifth report the Commissioners indicated the desirability of fixing a legal standard for sewage effluents, and suggested that such a standard should be based on (i) suspended solids and (ii) absorption of dissolved oxygen. Their contention then was that the two tests should be taken separately, and they suggested three parts per $x 00,000$ as the limit of suspended solids, and that the effluent after removal of its suspended solids should not absorb more than $0^{\circ} 5, \mathrm{I}$, and $\mathrm{x}_{5} 5$ parts dissolved oxygen per roo,ooo after one day's, two days', and five days' incubation at $65^{\circ} \mathrm{F}$. respectively.

In their present report the Commissioners recognise the difficulty of the separation of the suspended solids, and finally recommend the following as the normal legal standard, viz. : 3 parts per ıoo, ooo of suspended solids, and, including its suspended solids, the effluent shall not absorb more than 2 parts dissolved oxygen per IOO, 000 after five days' incubation at $65^{\circ} \mathrm{F}$.

The importance of this report lies in the fact that not only is a definite legal standard recommended, but that in the opinion of the Commissioners this standard should be a variable one, dependent on the conditions at the outfall, i.e. condition of river or stream receiving the effluent and relation of volume of sewage effluent to river water.

The Commissioners state that their experience leads them to think that if the dilution while not falling below I 50 volumes does not exceed 300 volumes, the dissolved oxygen test may be omitted and the standard for suspended solids fixed at 6 parts per 100,000 , and if the dilution while not falling below 300 volumes does not exceed 500, the standard for suspended solids may be further relaxed to $1_{5}$ parts per 100,000 , and with a dilution of more than 500 volumes all 
tests might be dispensed with and crude sewage discharged, subject to such conditions as to the provision of screens or detritus tanks as might appear necessary to the central authority.

In arriving at the proposed legal standard and modifications, the limit of the amount of dissolved oxygen absorbed by river water without creating a nuisance has been taken as a basis. The report contains data in regard to this point, and the method of determining the standard so far as regards the permissible amount of dissolved oxygen absorption is given. Tables are also given showing the amount of oxygen absorbed by typical sewage liquors and effluents, together with the theoretical amount of dilution necessary to prevent de-oxygenation beyond a certain limit.

E. A.

BIRTHMARKS AS A TEST OF RACE.

A SUGGESTION was recently made by Herr A Bealz that blue patches in the sacral region furnished a valuable test of race. Such marks are found among the children of Chinese, Koreans, Japanese, and Malays. Mr. Gait, Census Commissioner for India, directed that during the I9I I census inquiries should be made into the question. Much information on the subject will be found in Mr. C. M. Webb's Census Report of Burma for rgI I, recently issued (vol. i., pp. $28 \mathrm{I}$ et seq.). The results are not decisive, and there are at present no means of giving statistics showing the prevalence of these marks. But they are found extensively in Burma, and seem to indicate the existence of a Mongoloid strain in the population.

The question of Melanoglossia was also raised by Surgeon-Captain Maynard, I.M.S., and the prevalence of these black marks on the tongue was also investigated by Mr. Webb (ibid., i. 286), They are very infrequent among Aryan immigrants to Burma, but are found to a large extent among Dravidians, and the pigmentation of the tongue seems to vary with the pigmentation of the skin.

It may be hoped that the question will receive further attention in India, and that inquiries will be made on a wider scale to determine the statistical incidence of these marks.

\section{COLONEL J. S. BILLINGS, M.D.}

TH $\mathrm{HE}$ world of letters, as well as that of science, has sustained a very great loss in the death of Col. J. S. Billings, M.D., who died in New York on March $\mathrm{II}$, at the age of seventy-six. Although born in Indiana, and not in New England, he was nevertheless a typical example of what Oliver Wendell Holmes in "Elsie Venner" calls "the Brahmin caste of New England." In person he was tall and powerfully built. He had a well-poised and shapely head, clear-cut teatures and a very quiet, unassuming and courtly manner.

In spite of his quiet appearance and manner, Dr. Billings was a man of extraordinary energy. $\mathrm{He}$ joined the army of the Northern States in I 86 I as assistant surgeon, but he was medical inspector of the army of the Potomac when the war finished. During the var he aesizned most of the hospitals of the northern army. In 188 he took charge of the Surgeon-General's Library at Washington, a small collection of about two hundred books. During the twenty-two years in which he held the office of director he raised this collection to be one of the finest medical libraries in the world. The catalogue of the library is a stupendous work, giving references not only to medical books, but to pamphlets and extracts, so that it is now indispensable to every worker in medical literature.

From 1891 to 1896 Dr. Billings was professor of hygiene in the University of Pennsylvania, and in 1896 he became director of the New York Public Library, Astor, Lenox and Tilden foundations. This he determined to make one of the seven or eight great libraries of the world, comparable with the British Museum and the Vatican Libraries. He had the satisfaction during his lifetime of seeing a new building provided for the library and the number and value of the books greatly increased. In addition, he arranged for branch libraries to which books could be sent out and consulted apart from the library itself.

Probably no other single man ever did so much for libraries as Dr. Billings. His work was recognised during his lifetime by various universities. He received the honorary degree of LL.D. from five universities--Edinburgh, Harvard, Buda-Pesth, Yale and Johns Hopkins-the D.C.L. from Oxford and the M.D. from Munich and Dublin. But his labours in founding a complete bibliography of medicine by the SurgeonGeneral's Catalogue and the "Index Medicus," in devising a new method of library cataloguing, and in extending and amplifying the work of the New York Public Library so as to make it a great national institution, will only be fully appreciated by posterity. His kindness of heart his affectionate disposition and his charm of manner made him beloved by all who knew him, and it will be long indeed before we see his like again.

LAUDER BRUNTON.

\section{NOTES.}

THE Geological Society of France has awarded the Gaudry medal, the highest honour it can bestow, to Prof. Edward Suess, of the University of Vienna. The Fontannes prize for the best work in stratigraphical geology during the last five years has been awarded to $M$. Jean Boussac.

WE are asked to state that the Committee on $\mathrm{Re}$ search Institute, Chicago, is collecting information about bibliographical material and indexes kept in manuscript by libraries or individuals. Those who have such material in their possession, or know of the whereabouts of any, are desired to communicate with Mr. A. G. S. Josephson, care of the John Crerar Library, Chicago.

IN accordance with the recommendation of the Royal Commission on Vivisection, the Home Secretary has appointed an Advisory Committee to assist him

$$
\text { NO. 2264, VOL. 9I] }
$$

